\title{
The Regulation of Differentiation in Mesenchymal Stem Cells
}

\author{
Andrea Augello and Cosimo De Bari
}

\begin{abstract}
Mesenchymal stromal/stem cells (MSCs) are a population of stromal cells present in the bone marrow and most connective tissues, capable of differentiation into mesenchymal tissues such as bone and cartilage. MSCs are attractive candidates for biological cell-based tissue repair approaches because of their extensive proliferative ability in culture while retaining their mesenchymal multilineage differentiation potential. In addition to its undoubted scientific interest, the prospect of monitoring and controlling MSC differentiation is a crucial regulatory and clinical requirement. Hence, the molecular regulation of MSC differentiation has been extensively studied. Most of the studies are in vitro, because the identity of MSCs in their tissues of origin in vivo remains undefined. This review addresses the current knowledge of the molecular basis of differentiation of cultured MSCs, with a particular focus on chondrogenesis and osteogenesis. Building on the information coming from developmental biology studies of embryonic skeletogenesis, several signaling pathways and transcription factors have been investigated and shown to play critical roles in MSC differentiation. In particular, the Wnt and transforming growth factor- $\beta /$ bone morphogenetic protein signaling pathways are well known to modulate in MSCs the molecular differentiation into cartilage and bone. Relevant to the emerging concept of stem cell niches is the demonstration that physical factors can also participate in the regulation of MSC differentiation. Knowledge of the regulation of MSC differentiation will be critical in the design of three-dimensional culture systems and bioreactors for automated bioprocessing through mathematical models applied to systems biology and network science.
\end{abstract}

\section{Mesenchymal Stem Cells: A Brief Overview}

Mesenchymal stromal/stem cells (MSCs), a subset of stromal cells present at low frequency in most adult connective tissues, have been extensively studied for their multiple differentiation capabilities. Friedenstein and colleagues (1970) demonstrated that the bone marrow contains a rare population of plastic-adherent cells (approximately 1 in 10,000 nucleated cells) that were able to form single-cellderived colonies. The adherent cell clones expanded into round-shaped colonies composed of fibroblastoid cells, thus leading to the term colony-forming unit-fibroblasts (CFU-f); after proliferation some of the colonies could differentiate into aggregates resembling small areas of bone or cartilage (Friedenstein et al., 1970, 1976). These initial observations were then extended by the study of CFU-f proliferative abilities and phenotypic characteristics (Castro-Malaspina et al., 1980; Prockop, 1997; Caplan and Bruder, 2001). These cells were eventually defined as multipotent and able to differentiate into osteoblasts, chondrocytes, adipocytes, and even myoblasts.

\section{MSC Differentiation: The Caveat of In Vitro Studies}

MSCs have been studied in several species, especially humans (Castro-Malaspina et al., 1980; Haynesworth et al., 1992; Bruno et al., 2009; Yoo et al., 2009) and mice (Gindraux et al., 2007; Sung et al., 2008). MSCs are classically derived from bone marrow (Pittenger et al., 1999), but they have been isolated as well from most connective tissues (da Silva Meirelles et al., 2006), including, to mention a few, adipose tissue (Zuk et al., 2002), periosteum (Nakahara et al., 1991; De Bari et al., 2001a, 2006), and synovial membrane (De Bari et al., 2001b, 2003). From the accumulating studies in the literature, it is now apparent that MSCs, whichever their tissue source, have ability to respond to a variety of physiological or pathogenic stimuli, producing responses that in each specific context require thorough investigation in order to assess their biological significance and exploit any potential clinical impact.

The differentiation of MSCs has been extensively studied, using mainly well-established in vitro assays with cultureexpanded MSCs. Findings, therefore, have the caveat that 
they may not always be reliable and fully reproducible because of the vast heterogeneity of in vitro culture conditions and MSC types. Indeed, MSCs are known to undergo phenotypic rearrangements during ex vivo manipulations, losing expression of some markers while acquiring new ones (Jones et al., 2002). In addition, the possibility exists that the MSC phenotype and abilities vary between in vivo and in vitro settings because of the removal from their natural environment and the use of chemical and physical growth conditions that might alter their characteristics. The in vitro-obtained data are overly dependent on culture conditions for derivation and expansion of MSC populations and, therefore, are unlikely to be extrapolated to the native cells. Data may also not be entirely valid across species and intraspecies. As an example, murine MSCs differ not only from the human MSCs, but also between strains in marker expression and behavior in culture (Peister et al., 2004; Sung et al., 2008; Fiorina et al., 2009). Furthermore, data showed that MSCs from different tissues present phenotypic heterogeneity and different growth abilities (Baksh et al., 2007; Rebelatto et al., 2008), reflecting a tissue specificity that could be correlated to marked biological and functional differences (De Bari et al., 2008). Such heterogeneity could also underpin the regulation of MSCs and their responses to external stimuli, and it could be a main source of variation in the biological properties of MSCs. To complicate things further, studies on MSCs have not always been performed with primary cells but with cell lines such as C3H10T1/2 (Shea et al., 2003; Wang et al., 2010). This makes the reported findings not directly extrapolatable to primary human MSCs and of complex interpretation within the full biological picture.

Despite biological differences, MSCs from multiple tissue sources share common features such as the potential to differentiate into mesenchymal lineages and the expression of common surface markers (Baksh et al., 2007), although even within each tissue source, single-cell-derived clonal MSC populations are highly heterogeneous in their proliferative and differentiation potentials (Phinney and Prockop, 2007; De Bari et al., 2008).

\section{Differentiation Potency of Culture-Expanded MSCs}

One of the criteria to define MSCs is their ability to differentiate into the osteogenic, chondrogenic, and adipogenic lineages (Dominici et al., 2006). Classically, osteogenic differentiation of human MSCs (Jaiswal et al., 1997; Pittenger et al., 1999) requires incubation in fetal bovine serum (FBS)containing medium supplemented with ascorbic acid, $\beta$-glycerophosphate, and dexamethasone, resulting in an increase in alkaline phosphatase activity and calcium deposition. The chondrogenic differentiation is performed with a high cell-density pellet or micromass culture treated with transforming growth factor (TGF)- $\beta$ in serum-free medium; this results in production of cartilage-specific, highly sulfated proteoglycans and type II collagen. For adipogenic differentiation, MSCs are treated with dexamethasone, insulin, isobutyl methyl xanthine, and indomethacin (added to medium containing FBS), and the differentiation is revealed by the detection of lipid vacuoles with oil red $\mathrm{O}$ staining. At the clonal level, however, not all clonal populations are able to differentiate into all three lineages, as some MSC clones may lack differentiation into at least one lineage (Pittenger et al.,
1999). Subsequent studies indicated the possible existence of a hierarchical model of differentiation, with human bone marrow clonal MSC populations readily differentiating into the three lineages but undergoing a sequential loss of lineage potential with the osteogenic precursors as residual cells (Muraglia et al., 2000).

Increasing evidence, indeed, indicates that MSC populations are heterogeneous with coexisting subsets having varying potency; this applies to bone marrow MSCs as well as to MSCs from other tissues. As an example, we reported that human synovium-derived clonal MSCs were all capable of osteogenic and chondrogenic differentiation although with varying potency, but only $30 \%$ of the clonal populations tested were able to differentiate into adipocytes (Karystinou et al., 2009).

Under appropriate conditions, MSCs can also differentiate into other mesenchymal lineages such as skeletal myocytes and tenocytes (Wakitani et al., 1995; De Bari et al., 2003; Hoffmann et al., 2006). MSCs have also been reported to differentiate into nonmesenchymal lineages such as neurons (Black and Woodbury, 2001). The clinical relevance of the presumptive nonmesenchymal potency of MSCs is, however, questioned because, for example, MSC-derived neuron-like cells were unable to generate action potentials and, therefore, to function as neurons (Hofstetter et al., 2002).

\section{MSC-derived cartilage and bone}

The "natural" mesenchymal propensity of MSCs has prompted researchers to devote attention to the chondrogenic and osteogenic abilities of MSCs with the clinical prospects of developing MSC-based biological approaches to the repair of articular cartilage and bone. The osteogenic potential of culture-expanded MSCs (Friedenstein et al., 1976; Ashton et al., 1985) has been studied extensively in vitro and in vivo. The first in vivo experiments with MSCs were performed with diffusion chambers loaded with cultureexpanded cells (Ashton et al., 1980). Later, the adoption of bioscaffolds such as hydroxyapatite (HA) implanted in immunocompromised mice proved useful in studying MSC osteogenic differentiation in vivo (Ohgushi and Okumura, 1990). It was possible to obtain donor MSC-derived bone by subcutaneous implantation of HA scaffolds seeded with human MSCs (Muraglia et al., 1998; Bluteau et al., 2008; De Bari and Dell'Accio, 2008; De Bari et al., 2008; Dell'Accio et al., 2008). Using HA-based bioscaffolds, it then became possible to repair segmental bone defects in vivo by using autologous MSCs, under loaded conditions, both in large animals (Kon et al., 2000) as well as in humans in proof-of-concept studies (Quarto et al., 2001).

The use of MSCs in clinical practice remains challenging for issues such as the plethora of tissue sources and culture conditions, with resulting biological variability. For instance, human periosteum contains cells that after enzymatic release and culture expansion display the MSC phenotype and capacity at the single-cell level to differentiate into multiple skeletal lineages including bone (De Bari et al., 2006). Notably, in a proof-of-concept study we quantified the boneforming potency of matched human MSCs from synovium and periosteum and analyzed the sources of variability in osteogenic outcome. We identified the tissue of origin of MSCs as the main source of variability, because MSCs from 
periosteum had significantly greater osteogenic potency than MSCs from synovium. A second source of variability was related to the individual donor, within each tissue. We measured the basal expression levels of osteoblast-lineage genes in clonal MSCs before osteogenic treatment, identified biomarkers that correlated with osteogenic outcome, and developed a mathematical model that predicts bone-forming potency of clonal MSC preparations, independent of donor and tissue source (De Bari et al., 2008). The development of a biomarker-based model that predicts the bone-forming potency of human MSC preparations is of considerable clinical relevance. A similar approach is likely to increase the consistency of therapies that employ MSCs for bone repair. It may also facilitate the selection of individuals that qualify for MSC-based bone repair and help identify the best source of and preparation protocol for human MSCs. It remains to be investigated whether the same formula can be applied successfully to MSC-based orthotopic bone repair in a preclinical model, where in addition to the properties intrinsic to the cell preparation, other factors such as inflammation and biomechanics will influence bone formation.

Although bone formation in vivo is relatively straightforward when MSCs are loaded onto matrices and then implanted subcutaneously in mice, the formation in vivo of stable hyaline-like cartilage resembling articular cartilage appears to be challenging when using MSCs. The chondrogenic potential of MSCs is well known in vitro in high-celldensity pellets or micromass cultures but the key question as to whether the resulting cartilage-like tissue is stable cartilage or a transient cartilage template destined to be replaced with bone in a process of endochondral ossification is unresolved. Using a nude mouse assay of ectopic cartilage formation validated with intramuscular injection of adult human articular chondrocytes (Dell'Accio et al., 2001), we demonstrated that the in vitro chondrogenic potential of synovial membrane-derived MSCs is not sufficient to predict the in vivo outcome at least in this nude mouse model, because the synovial MSCs induced in vitro into a chondrocyte-like phenotype failed to form stable cartilage when implanted in vivo (De Bari et al., 2004). Of note, Pelttari and colleagues reported that bone marrow MSC-derived cartilage pellets transplanted into ectopic sites in severe combined immunodeficiency (SCID) mice underwent endochondral ossification, via premature induction of chondrocyte hypertrophy-related molecules such as type $X$ collagen (Pelttari et al., 2006). More recently, Scotti and colleagues (2010) reported that human bone marrow MSCs, implanted subcutaneously into nude mice at various stages of chondrogenic differentiation, formed bone only when they had developed in vitro hypertrophic cartilage traits. The underlying morphogenetic process was similar to limb bone development in embryos, thus revealing the capacity of human MSCs to generate bone tissue via an endochondral program.

Altogether, these studies suggest that the in vitro MSCderived neoformed cartilage-like tissue is not stable. Nonetheless, they do not rule out the possibility that, as opposed to an ectopic site, the joint environment of a cartilage defect may instead be sufficient either to induce a stable cartilage phenotype or stabilize the chondrocyte-like phenotype of in vitro precommitted MSC populations. Uplift of the bone front at the expense of the overlying articular cartilage has, however, been observed in osteochondral repair by bone marrow cells (Qiu et al., 2003).

\section{Molecular Regulation of MSC Differentiation}

Several molecules have been reported to be involved in the regulation of MSC differentiation. In this review we focus on the main signaling pathways involved in the modulation of MSC differentiation but will also sketch out a concise overview of the transcription factors and the physical parameters influencing the fate of MSCs. Because studies of developmental biology have inspired a great deal of investigation in the MSC field, we think it will be helpful to report key findings in embryonic skeletogenesis before discussing the relevant pathways in MSC differentiation. Our attention revolves mainly around the Wnt canonical pathway and the TGF- $\beta$ superfamily pathways.

\section{Wnt signaling and MSC differentiation}

Particularly studied is the Wnt family of secreted proteins, reported to modulate bone mass in vivo and shown as acting directly on MSCs (Liu et al., 2009; Takada et al., 2009). Wnt genes, a family of 19 genes in humans and mice, produce secreted proteins that, for their involvement in cell proliferation, differentiation, and apoptosis, are crucial in embryonic tissue development and in regeneration of adult tissues including bone (Westendorf et al., 2004). Figure 1 shows a schematic diagram of the canonical $\beta$-catenin-dependent Wnt signaling pathway (for a comprehensive review see Gordon and Nusse, 2006).

Several studies of developmental biology using mouse genetics have revealed a critical role for Wnt in skeletogenesis, and particularly in the formation of cartilage and bone. We briefly review those studies that, in our opinion, are relevant for an understanding of the molecular regulation of MSC differentiation.

Wnt and bone. Wnt proteins have a critical role in bone development and homeostasis. Gong and colleagues (2001) demonstrated that the osteoporosis-pseudoglioma syndrome (OPPG), a disorder characterized by low bone mass, ocular defects, and predisposition to fractures, was caused by a lossof-function mutation in the LRP5 (low-density lipoprotein receptor-related protein-5) coreceptor. The production of Lrp5 $^{-/-}$mice (Kato et al., 2002) and $\mathrm{Lrp6}^{-/-}$mice (Holmen et al., 2004) allowed recapitulaton of these findings, with phenotypes similar to that of human OPPG. When the mutation of Lrp5 was involved, the disease was attributed to decreased osteoblast proliferation. Interestingly, other mutations in the same gene can have different effects. As an example, some individuals with high bone mass density bear a gain-of-function mutation in Lrp5 (Boyden et al., 2002; Little et al., 2002). Many studies followed these initial reports, indicating that loss-of-function mutations in the Lrp5 gene could also affect bone formation via indirect mechanisms, such as Htr1b (5-hydroxytryptamine [serotonin] receptor1B)-CREB (cAMP response element-binding protein) (Yadav et al., 2008), but also that the gain-of-function mutation in Lrp5 may not have an effect on bone density when expressed in mature osteoblasts (Yadav et al., 2008). It appears therefore that Lrp5 could affect bone mass in a Wnt-independent way and that Lrp6 could be more relevant when considering Wnt signaling in osteoblasts. When analyzing the Wnt pathway 


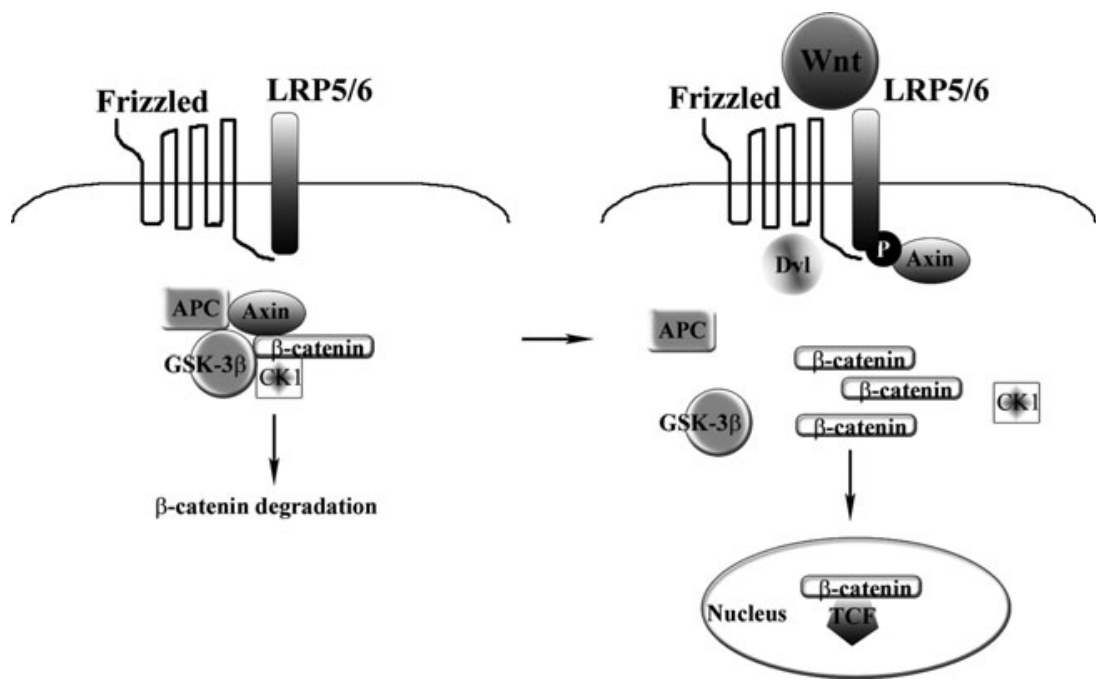

FIG. 1. Schematic diagram of the canonical Wnt signaling pathway. In the absence of Wnt ligand, $\beta$-catenin is phosphorylated by GSK-3 $\beta$ and is degraded. On engagement of Wnt ligands with their receptors, the cytoplasmic degradation complex of $\beta$-catenin is disrupted; $\beta$-catenin accumulates and translocates into the nucleus, where it interacts with TCF/LEF and activates transcription of target genes. APC, adenomatous polyposis coli protein; CK1, casein kinase-1; Dv1, disheveled protein; GSK-3 $\beta$, glycogen synthase kinase-3 $\beta$; LRP5/6, low-density lipoprotein receptor-related protein-5/6; $\mathrm{P}$, phosphorylation; TCF/LEF, T-cellspecific transcription factor/lymphoid enhancer-binding factor.

involved in bone development and homeostasis, it is apparent that each molecule involved can affect different features of bone mass regulation (for a comprehensive list of Wnt-related factors and the in vivo effects caused by them, see the review by Hoeppner and colleagues, 2009).

Wnt and cartilage. Wnt genes and proteins also act on cartilage differentiation, by interacting with cartilage-related transcription factors. Day and colleagues (2005) showed that ectopic canonical Wnt signaling led to enhanced ossification and suppression of chondrocyte formation during skeletogenesis. On the other hand, during both intramembranous and endochondral ossification, by genetic inactivation of $\beta$-catenin they induced ectopic chondrocyte formation in place of osteoblast differentiation.

In the same year, Hill and colleagues (2005) demonstrated that canonical Wnt signaling was essential for skeletal lineage differentiation, preventing transdifferentiation of osteoblastic cells into chondrocytes, and also that $\beta$-catenin was crucial in determining whether mesenchymal progenitors would become osteoblasts in the developing embryo.

Dong and colleagues (2006) investigated the molecular mechanisms underlying canonical Wnt-mediated regulation of chondrocyte hypertrophy, using chick sternal chondrocytes, and provided evidence that in chick upper sternal chondrocytes activation of the canonical $\beta$-catenin Wnt signaling pathway induces chondrocyte hypertrophy and maturation and that $\mathrm{Wnt} / \beta$-catenin signaling is regulated by TGF- $\beta$ and bone morphogenetic protein (BMP)-2, and mediates chondrocyte hypertrophy at least partly through activation of Runx2, a transcription factor required for bone formation (Schroeder et al., 2005; Komori, 2010), which in turn may induce expression of collagen type $X$.

Maruyama and colleagues (2010) observed endochondral ossification in vivo in the skull of mice via knockout of Axin2, a negative regulator of the $\mathrm{WNT} / \beta$-catenin pathway. The activation of $\beta$-catenin cooperated with fibroblast growth factor receptor-1 (FGFR1) to alter the lineage commitment of MSCs to differentiate into chondrocytes. In this way, instead of the expected intramembranous ossification, the switch in the fate of MSCs to chondrocytes resulted in endochondral ossification, abnormal suture morphogenesis, and fusion with premature cranial gaps closure and a phenotype of craniosynostosis. These findings suggest that the WNT/ $\beta$-catenin pathway is involved in controlling the stem cell population by regulating its renewal and proliferation, and in modulating lineage specification, in part by setting the balance of the FGF and BMP pathways (Maruyama et al., 2010).

Wnt and MSCs. Attention has moved from osteoblasts to the cells that likely originate them, the MSCs. Etheridge and colleagues (2004) demonstrated that MSCs express a number of Wnt ligands, including Wnt2, Wnt4, Wnt5a, Wnt11, and Wnt16, and several Wnt receptors, including FZD2, 3, 4, 5, and 6 as well as various coreceptors and Wnt inhibitors. Boland and colleagues (2004) showed that during osteogenic differentiation in vitro, MSCs upregulate a number of Wntrelated molecules while downregulating others. Moreover, the same authors demonstrated that MSCs could respond to exogenous Wnt3, resulting in transient repression of osteogenesis. Similar results were obtained by $\mathrm{Cho}$ and colleagues (2006) using human adipose-derived MSCs. Using an in vitro differentiation culture system with human MSCs and performing global gene expression profiling on undifferentiated and differentiated MSCs, as well as on dedifferentiated cells derived from mesenchymal lineages, Song and colleagues demonstrated that differentiated cells could dedifferentiate into a primitive stem cell-like stage before transdifferentiating into another cell type (Song et al., 2006). In this study, the authors identified a list of genes that were candidate markers of MSCs and may function to maintain stem cells in an uncommitted state or to initiate their differentiation process. Prominent among them were the genes associated with the Wnt pathway.

Quarto and colleagues (2010) reported that Wnt3a has differential effects when using different in vitro models and an in vivo model of bone regeneration; the effects were dependent on the dose as well as the differentiation state of the recipient cell. When added to undifferentiated MSCs, Wnt3a inhibited osteogenic differentiation. By contrast, when added to calvarial osteoblasts, Wnt3a at high doses had an inhibitory effect in cells from juvenile mice but induced bone production in cells from adult animals, as assessed by alkaline phosphatase activity and alizarin red mineralization assay. The defect repair was influenced once again both by 
the Wnt3a dose and by the age of the animal, mimicking the in vitro results. These findings are in accordance with previous investigations (Kahler and Westendorf, 2003; Kahler et al., 2006, 2008; Eijken et al., 2008), showing that the effect of canonical Wnt signaling on osteogenesis is influenced by the differentiation stage of target cells. Overall, canonical Wnt signaling appears to stimulate the differentiation of MSCs committed to osteogenic lineage, while it inhibits the terminal differentiation of mature osteoblasts.

In a study on the effects of Wnt inhibitors on MSC chondrogenesis, Im and Quan (2010) found that in pellet cultures of human MSCs, inhibitors of the Wnt pathway promoted early chondrogenesis of MSCs, but they lacked a synergistic effect with TGF- $\beta$ in the longer term culture, and therefore did not provide an ultimately enhancing role in the cartilage tissue engineering of MSCs.

The Wnt family and their regulation by microRNAs. Increasing attention has been devoted to the interaction between microRNAs and the classical differentiation pathways. Although many of such studies are on osteoblasts and not on undifferentiated MSCs, the results are relevant as they could be translated to primary MSC cultures and, possibly, to in vivo scenarios. It was reported that the microRNA miR-29a is induced by canonical Wnt signaling and can potentiate Wnt signaling (Kapinas et al., 2010). The microRNA miR$125 \mathrm{~b}$ inhibited osteoblastic differentiation and proliferation (Mizuno et al., 2008). After it was demonstrated that miR-27 could influence adipogenesis and myogenesis (Feng et al., 2009; McDaneld et al., 2009), Wang and Xu (2010) reported that the miR-27 microRNA is also able to interfere with the differentiation of a fetal osteoblastic cell line through Wnt signaling modulation, by accumulation of $\beta$-catenin and repression of adenomatous polyposis coli protein (APC) expression.

\section{TGF- $\beta$ superfamily signaling pathways and MSC differentiation}

The TGF- $\beta$ superfamily consists of many growth factors and morphogens that have roles in developmental skeletogenesis and postnatal skeletal homeostasis. The TGF- $\beta$ superfamily of ligands includes bone morphogenetic proteins (BMPs), growth and differentiation factors (GDFs), antimüllerian hormone (AMH), Activin, Nodal, and TGF- $\beta$ (Piek et al., 1999; Derynck and Miyazono, 2008). Here, we concentrate on the TGF- $\beta$ and BMP families, and on the effects that they exert on the skeletal system and on MSCs (see Fig. 2 for a schematic representation of the TGF- $\beta$ and BMP signaling pathways).

TGF- $\beta$ family. The expression of growth factors of the TGF- $\beta$ superfamily has been described in embryonic bone and cartilage development as well as during adult bone repair (Hogan, 1996; Horner et al., 1998), and the chondro/ osteo-stimulatory/modulatory effects of the TGF- $\beta$ s as well as the BMPs have been well established in embryonic and adult mesenchymal cells (Johnstone et al., 1998; Mackay et al., 1998; Denker et al., 1999; Barry et al., 2001; Majumdar et al., 2001; Noth et al., 2002; Sekiya et al., 2002). In particular, TGF$\beta$ has been used for years in in vitro assays of cartilage micromasses or pellets starting from culture-expanded MSCs (Mackay et al., 1998; Pittenger et al., 1999), and has become a requirement for these chondrogenesis assays. TGF- $\beta$ promotes cartilage-specific gene expression through intracellular signaling cascades involving SMAD proteins, the mitogenactivated protein (MAP) kinases, p38, extracellular-signal regulated kinase (ERK)-1, and c-Jun N-terminal kinase (JNK) (Lutz and Knaus, 2002; Schmierer and Hill, 2007).

After the demonstration of the crucial role of the cell adhesion protein, $\mathrm{N}$-cadherin, and Wnt signaling in mesenchymal
FIG. 2. Schematic diagram of the transforming growth factor (TGF)$\beta$ and bone morphogenetic protein (BMP) signaling pathways. On engagement of the ligands with their corresponding receptors, receptor SMADs are phosphorylated and form a complex with SMAD4, which enters the nucleus and interacts with transcription factors (TFs) to modulate gene transcription. SMAD2 and SMAD3 mediate TGF- $\beta$ signaling, whereas SMAD1, SMAD5, and SMAD8 mediate BMP signaling. The inhibitory SMAD6 and SMAD7 are also shown. BMPRI/II, BMP receptors I and II; TGF $\beta$ RI/II, TGF- $\beta$ receptors I and II.

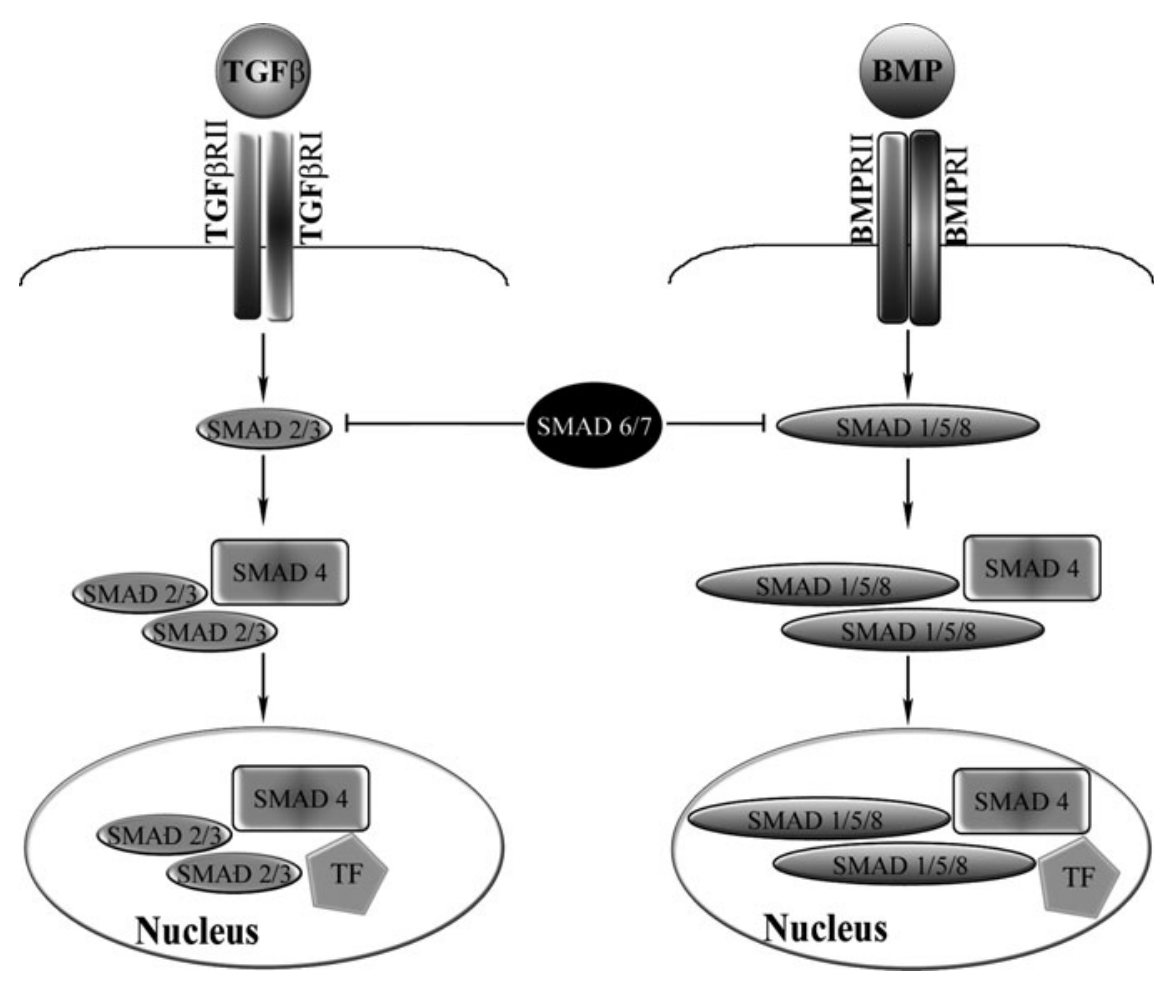


condensation and chondrogenesis (Fischer et al., 2002), Tuli and colleagues (2003) demonstrated that TGF- $\beta_{1}$ treatment initiates and maintains chondrogenesis of MSCs through the differential chondrostimulatory activities of p38, ERK-1, and to a lesser extent, JNK. This resulted in the modulation of $\mathrm{N}$ cadherin expression levels, WNT-7A gene expression, and the consequent Wnt-mediated signaling through the intracellular $\beta$-catenin pathway, with control of the condensation and early steps of MSC chondrogenesis.

BMP family. BMPs are involved in the developmental and homeostatic processes of the bone and cartilage, as well as of other tissues (Katagiri and Miyazono, 2008). BMPs are characterized by a complex transduction pathway, based on their signaling through SMAD proteins $1,5,8$, and 4 (reviewed in Xiao et al. [2007] and in Miyazono et al. [2010]). BMPs are capable of inducing, in adult rodents, ectopic cartilage and bone formation, mimicking embryonic endochondral bone formation.

BMPs are important morphogens regulating chondrogenesis and skeletogenesis during normal embryonic development (Hogan, 1996). Individual BMPs exhibit distinct expression patterns in skeletal elements. Bmp-2 is expressed in areas surrounding the initial cartilage condensations, periosteal and osteogenic zones, whereas Bmp-4 is expressed in perichondrium. Bmp-6 is expressed in prehypertrophic chondrocytes. High levels of Bmp-7 mRNA have been observed in the perichondrium, but its expression is absent in the zones of joint formation (Zhao et al., 2002; Sekiya et al., 2005).

The effects of BMPs on MSCs have been investigated in several studies. Rickard and colleagues (1994) demonstrated that rat bone marrow MSCs cultured in the presence of BMP2 increased osteoblastic markers such as alkaline phosphatase activity and expression of osteocalcin. This effect was strengthened when culturing MSCs with BMP-2 and dexamethasone together. Several other studies analyzed the effect of BMP-2, along with other factors, on the proliferative and osteogenic abilities of primary or immortalized MSCs and/ or osteoblasts (Wang et al., 1993; Hanada et al., 1997; Lecanda et al., 1997; Jorgensen et al., 2004). In 1999, Denker and colleagues observed that the addition of BMP-2 to C3H10T1/2 mesenchymal cells in micromass cultures enhanced the appearance of chondrocytes. The effect of BMP-2 was apparently modulated by $\mathrm{N}$-cadherin, a $\mathrm{Ca}^{2+}$-dependent adhesion molecule (Haas and Tuan, 1999). The addition of BMP-6 to micromass cultures of human bone marrow MSCs enhanced cartilage formation compared with controls in a time- and dose-dependent fashion (Sekiya et al., 2001).

In a study in micromass culture, Sekiya and colleagues (2005) compared the chondrogenic effect of BMP-2, BMP-4, and BMP- 6 on human bone marrow MSCs and observed that the most potent chondroinductor was BMP-2. Analyzing microarray data from the micromasses cultured with the various BMPs, the authors found that only the MSCs cultured with BMP-2 expressed the cartilage synthesis-related genes with the correct pattern and time sequence.

Using human MSCs from periosteum, we detected expression of BMP receptors and confirmed the chondrogenic effect of BMPs in micromass. However, BMP-2, BMP-4, BMP-7, and GDF-5/CDMP-1 (cartilage-derived morphogenetic protein-1) were poorly chondrogenic in comparison with TGF- $\beta_{1}$ (De Bari et al., 2001a).
BMP2 signaling can influence the Wnt pathway through interaction between $\beta$-catenin and $\mathrm{N}$-cadherin. Treatment of the mesenchymal cell line C3H10T1/2, in micromass culture with lithium chloride, a mimetic of canonical Wnts that acts by inhibiting glycogen synthase kinase (GSK)-3 $\beta$ serine/ threonine phosphorylation activity, significantly inhibited BMP-2 stimulation of chondrogenesis (Fischer et al., 2002), and decreased the levels of N-cadherin protein and mRNA, probably affecting mesenchymal condensation (see also Tuan, 2003), a process characterized by increased cell density and cell-cell adhesion and critical in the initiation of chondrogenic differentiation. In 2005, Modarresi and colleagues (2005) found that normal levels of N-cadherin expression were essential, in micromass pellet cultures, to obtain proper temporal MAP kinase and BMP-2 regulation of chondrogenic genes such as type II collagen, aggrecan, and Sox9.

Eyckmans and colleagues (2010) highlighted a requirement for BMP and Wnt signaling in bone formation when using human periosteum-derived MSCs seeded onto calcium phosphate carriers and implanted ectopically in immunedeficient mice. The inhibition of endogenous BMP and Wnt signaling by overexpression of the secreted antagonists Noggin and Frzb, respectively, abrogated osteoinduction.

\section{Other signaling molecules in MSC differentiation}

Other factors are known to influence the differentiation of MSCs. Many of them also interact, at different levels, with the Wnt and/or TGF- $\beta$ /BMP pathways. One of those factors, fibroblast growth factor (FGF)-2, has been shown to promote cell proliferation and to maintain the MSC population in a prolonged undifferentiated state (Martin et al., 1997). Ng and colleagues (2008) studied the transcriptional profiling of MSCs and of MSC-derived differentiated cells in order to identify the factors implied in the differentiation processes in vitro. From their analysis, the authors highlighted three pathways, centered on TGF- $\beta$, FGF-2, and platelet-derived growth factor (PDGF), which proved to be important in the growth and essential in the differentiation of MSCs. Furthermore, the authors were able to grow MSCs using a combination of these growth factors in culture, under serumfree conditions.

PDGF has been shown to inhibit osteogenic differentiation (Gruber et al., 2004; Kratchmarova et al., 2005). In an elegant study, Kratchmarova and colleagues found that the osteogenic differentiation of human MSCs is stimulated by epidermal growth factor (EGF) but not PDGF. They used mass spectrometry-based proteomics to compare proteins that were tyrosine phosphorylated in response to EGF and PDGF. More than $90 \%$ of these signaling proteins were used by both ligands, whereas the phosphatidylinositol-3-kinase (PI3K) pathway was activated exclusively by PDGF, implicating it as a possible control point. Indeed, chemical inhibition of PI3K in PDGF-stimulated cells removed the differential effect of the two growth factors, conferring full differentiation effect onto PDGF.

$\mathrm{Ng}$ and colleagues (2008) showed that inhibition of PDGF signaling resulted, instead, in fewer osteocytes and the absence of mineralized bone nodules, implying that under specific conditions PDGF may be required for correct osteogenic differentiation. Tokunaga and colleagues (2008) studied the effects of the $\beta$ receptor for PDGF, PDGFR- $\beta$, by 
specific PDGFR- $\beta$ gene deletion using Cre-loxP technology. Depletion of PDGFR- $\beta$ in MSCs decreased the mitogenic and migratory responses and enhanced osteogenic differentiation. In a mouse model of bone fracture, depletion of PDGFR- $\beta$ significantly increased the ratio of woven bone to callus. The effects of PDGFR- $\alpha$ on osteogenic differentiation were instead very subtle. PDGFR- $\beta$ could therefore represent an important target for bone tissue engineering.

MSCs express EGF receptor (EGFR)/ErbB-1, and EGF exerts mitogenic activity on MSCs (Krampera et al., 2005; Tamama et al., 2006). The role of EGFR signaling in bone is not well understood, with contrasting results having been discerned. Loss of EGFR signaling has been reported to accelerate chondrocyte and osteoblast differentiation in mice, suggesting that EGFR signaling negatively regulates bone cell differentiation (Sibilia et al., 2003). Satomura and colleagues reported that after transplantation of human MSCloaded HA scaffolds, the MSCs able to form bone were found to have consistently low expression of EGFR compared with those MSCs not forming bone, although individual variability could not be disregarded (Satomura et al., 1998). Activation of EGFR is also associated with enhanced proliferation of the stem/progenitor cell compartment with no impairment of differentiation (Krampera et al., 2005; Tamama et al., 2006), or even enhancement of differentiation (Kratchmarova et al., 2005). A reversible EGF-driven enhancement of in vitro osteogenic differentiation was described when incubating MSCs with tethered EGF (Platt et al., 2009), probably due to a consistent and continuous interaction between EGF and its receptor. This finding in particular could lead to the development of novel bioscaffold-based tissue-engineering approaches exploiting the tethering of active substances, such as EGF, that are never released from the bioscaffold itself and are therefore constantly available to induce an otherwise reversible differentiation process.

Other signaling molecules are involved in the chondro/ osteogenic differentiation pathways. Scotti and colleagues (2010) linked the in vivo endochondral ossification obtained in ectopic implants in nude mice of in vitro-engineered human MSCs to the regulation of Indian hedgehog (IHH) as an upstream signal through its receptor Patched1 (PTCH1), and GLI1 as mediator of IHH signal transduction. All these genes were either not expressed or expressed at low levels in culture-expanded MSCs, whereas their expression levels were markedly increased in the early hypertrophic and even more in the late hypertrophic constructs, indicating that the processes leading to endochondral ossification are equally regulated by the activation and/or upregulation of the signaling pathways involved in endochondral bone formation during embryonic limb skeletogenesis (Karsenty, 2008).

\section{Transcription factors in MSC differentiation}

Many transcription factors (TFs) intervene in the control and regulation of the differentiation pathways of MSCs. Once again, the developmental studies have provided an educational platform for investigations of the roles in MSC differentiation of those transcription factors that have been reported to be key regulators of embryonic skeletogenesis. In particular, the main transcription factors intervening in osteogenic differentiation are CBFA-1/Runx2 and Osterix
(Osx), known to be required for bone formation during development (Schroeder et al., 2005; Komori, 2010), whereas Sox9 is a transcription factor required for cartilage formation (Akiyama et al., 2004; Quintana et al., 2009). It must be said, however, that developmental studies have addressed in great detail the formation of cartilage that undergoes hypertrophy and is replaced with bone during endochondral ossification of limb development, whereas the molecular machinery underlying the formation of stable articular cartilage remains to be defined.

During development, chondrogenesis is controlled by interactions between Sox9 and the Wnt $/ \beta$-catenin signaling pathway. Either overexpression of Sox9 or inactivation of $\beta$-catenin in chondrocytes of mouse embryos in vivo produced a similar phenotype of dwarfism with decreased chondrocyte proliferation, delayed hypertrophic chondrocyte differentiation, and endochondral bone formation (Akiyama et al., 2004). Furthermore, either inactivation of Sox9 or stabilization of $\beta$-catenin in chondrocytes also resulted in a similar phenotype of severe chondrodysplasia. Sox9 markedly inhibited activation of $\beta$-catenin-dependent promoters and stimulated degradation of $\beta$-catenin. Of note, a physical interaction between $\beta$-catenin and the C-terminal trans-activation domain of Sox9 was demonstrated.

Dong and colleagues (2006) observed upregulation of type $X$ collagen (col10a1) and Runx 2 mRNA by viral overexpression of Wnt8c and Wnt9a, thereby inducing chondrocyte hypertrophy. Wnt8c and Wnt9a strongly inhibited mRNA levels of Sox9 and type II collagen (col2a1). They also found that Wnt8c further enhanced BMP-2-induced expression of Runx2 and col10a1, whereas Wnt8c and Wnt9a inhibited TGF- $\beta$-induced expression of Sox 9 and col2a1. By overexpressing $\beta$-catenin, the authors upregulated Runx2, col10a1, and alkaline phosphatase (AP) mRNA levels while they inhibited col2a1 transcription; Wnt $8 \mathrm{c}$ and $\beta$-catenin also acted at protein levels, inducing production of Runx2 in chondrocytes. These results link activation of the canonical Wnt signaling pathway with chondrocyte hypertrophy and maturation through the transcription factors Runx2 and Sox9.

Klees and colleagues (2005) found that adhesion of cultured MSCs to laminin-5 activated ERK, leading to phosphorylation of Runx2/CBFA-1. Majumdar and colleagues (2001) observed that in MSCs placed in alginate beads and cultured in serum-free medium with BMP-2 and BMP-9 there was increased expression of Sox 9 accompanied by an increase in expression of mature chondrocyte markers such as type II collagen.

It has been reported that RUNX2 and SOX9 physically interact in MSCs and that SOX9 can inhibit the trans-activation of RUNX2. In addition, RUNX2 exerts reciprocal inhibition on SOX9 trans-activity. SOX9 induced degradation of RUNX2, which was proteasome independent but phosphorylation dependent, and required the presence of the RUNX2 C-terminal domain, which contains a nuclear matrix-targeting sequence. Furthermore, SOX9 was able to decrease the level of ubiquitinated RUNX2 and direct RUNX2 to the lysosome for degradation. SOX9 also directed $\beta$ catenin for lysosomal breakdown (Cheng and Genever, 2010). Thus, the reciprocal regulation between SOX9 and RUNX2, downstream of signaling pathways, will have obvious consequences on MSC fate. 


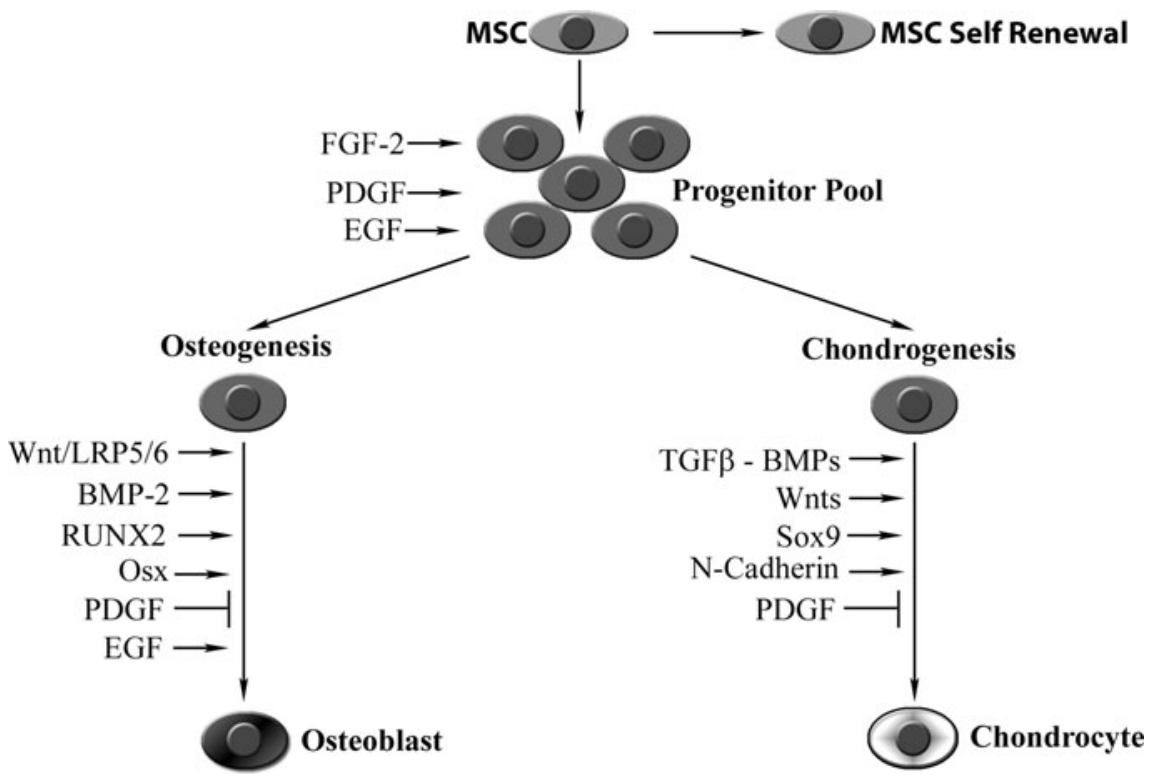

FIG. 3. Schematic overview of signaling molecules and transcription factors involved in the regulation of chondro-osteogenic differentiation of MSCs. BMP-2, bone morphogenetic protein-2; EGF, epidermal growth factor; FGF-2, fibroblast growth factor2; LRP5/6, low-density lipoprotein receptor-related protein-5/6; Osx, Osterix; PDGF, platelet-derived growth factor; RUNX2, runt-related transcription factor-2; TGF- $\beta$, transforming growth factor- $\beta$.

\section{Physical factors in MSC differentiation}

MSCs also interact physically with the surrounding environment. Examples are numerous; here we cite but a few. The first line of interaction for MSCs is with the extracellular environment, be it plastic, a resorbable bioscaffold, or a more rigid structure. Seminal in this sense is the study by Engler and colleagues (2006), showing that the extracellular matrix can control stem cell fate, inducing seeded MSCs toward osteogenesis or chondrogenesis depending on its physical properties. More recently, it was reported that manipulation of the membrane potential of cultured MSCs can influence their fate and differentiation (Sundelacruz et al., 2008, 2009). These findings open up unprecedented avenues for the regulation of MSC differentiation in regenerative medicine using physical factors, without the use of exogenous growth factors.

\section{Conclusion}

There is an increasing amount of data on the molecular regulation of MSC differentiation, and this review has addressed only some of them (for a schematic overview see Fig. 3). As already discussed previously, a caveat of the in vitro studies relates to the known variability that is at least in part due to culture conditions and the MSC type used. Therefore, a priority in the MSC field is the standardization of isolation and culture expansion. This will minimize variability of outcome and will also allow proper comparison of studies. Nonetheless, the availability of standardized in vitro assays employing primary human MSCs has huge scientific and clinical potentials. The use of reporter assays for assessment of net signaling activation, three-dimensional culture systems, and bioreactors with sensors monitoring MSC activity will allow rapid progression from basic science to automated, highly controlled cell-bioprocessing methods monitored via mathematical models through technological advances in systems biology and network science. With this view, the investigation of MSC "omics" as well as of the influence of the surrounding niches and contained signaling molecules is of paramount importance. A deep knowledge of the mechanisms underlying MSC differentiation will be paramount for the successful development of consistent MSC-based products in tissue engineering and regenerative medicine.

\section{Acknowledgments}

Supported by MRC grant G108/620. Professor De Bari is a Fellow of the Medical Research Council, UK.

\section{Author Disclosure Statement}

The authors have nothing to disclose.

\section{References}

Akiyama, H., Lyons, J.P., Mori-Akiyama, Y., Yang, X., Zhang, R., Zhang, Z., Deng, J.M., Taketo, M.M., Nakamura, T., Behringer, R.R., McCrea, P.D., and De Crombrugghe, B. (2004). Interactions between Sox 9 and $\beta$-catenin control chondrocyte differentiation. Genes Dev. 18, 1072-1087.

Ashton, B.A., Allen, T.D., Howlett, C.R., Eaglesom, C.C., Hattori, A., and Owen, M. (1980). Formation of bone and cartilage by marrow stromal cells in diffusion chambers in vivo. Clin. Orthop. Relat. Res. (151), 294-307.

Ashton, B.A., Abdullah, F., Cave, J., Williamson, M., Sykes, B.C., Couch, M., and Poser, J.W. (1985). Characterization of cells with high alkaline phosphatase activity derived from human bone and marrow: Preliminary assessment of their osteogenicity. Bone 6, 313-319.

Baksh, D., Yao, R., and Tuan, R.S. (2007). Comparison of proliferative and multilineage differentiation potential of human mesenchymal stem cells derived from umbilical cord and bone marrow. Stem Cells 25, 1384-1392.

Barry, F., Boynton, R.E., Liu, B., and Murphy, J.M. (2001). Chondrogenic differentiation of mesenchymal stem cells from bone marrow: Differentiation-dependent gene expression of matrix components. Exp. Cell Res. 268, 189-200.

Black, I.B., and Woodbury, D. (2001). Adult rat and human bone marrow stromal stem cells differentiate into neurons. Blood Cells Mol. Dis. 27, 632-636. 
Bluteau, G., Luder, H.U., De Bari, C., and Mitsiadis, T.A. (2008). Stem cells for tooth engineering. Eur. Cell. Mater. 16, 1-9.

Boland, G.M., Perkins, G., Hall, D.J., and Tuan, R.S. (2004). Wnt 3a promotes proliferation and suppresses osteogenic differentiation of adult human mesenchymal stem cells. J. Cell. Biochem. 93, 1210-1230.

Boyden, L.M., Mao, J., Belsky, J., Mitzner, L., Farhi, A., Mitnick, M.A., Wu, D., Insogna, K., and Lifton, R.P. (2002). High bone density due to a mutation in LDL-receptor-related protein 5. N. Engl. J. Med. 346, 1513-1521.

Bruno, S., Bussolati, B., Grange, C., Collino, F., Di Cantogno, L.V., Herrera, M.B., Biancone, L., Tetta, C., Segoloni, G., and Camussi, G. (2009). Isolation and characterization of resident mesenchymal stem cells in human glomeruli. Stem Cells Dev. $18,867-880$.

Caplan, A.I., and Bruder, S.P. (2001). Mesenchymal stem cells: Building blocks for molecular medicine in the 21st century. Trends Mol. Med. 7, 259-264.

Castro-Malaspina, H., Gay, R.E., Resnick, G., Kapoor, N., Meyers, P., Chiarieri, D., McKenzie, S., Broxmeyer, H.E., and Moore, M.A. (1980). Characterization of human bone marrow fibroblast colony-forming cells (CFU-F) and their progeny. Blood 56, 289-301.

Cheng, A., and Genever, P.G. (2010). SOX9 determines RUNX2 transactivity by directing intracellular degradation. J. Bone Miner. Res. (in press). doi: 10.1002/jbmr.174.

Cho, H.H., Kim, Y.J., Kim, S.J., Kim, J.H., Bae, Y.C., Ba, B., and Jung, J.S. (2006). Endogenous Wnt signaling promotes proliferation and suppresses osteogenic differentiation in human adipose derived stromal cells. Tissue Eng. 12, 111-121.

da Silva Meirelles, L., Chagastelles, P.C., and Nardi, N.B. (2006). Mesenchymal stem cells reside in virtually all post-natal organs and tissues. J. Cell Sci. 119, 2204-2213.

Day, T.F., Guo, X., Garrett-Beal, L., and Yang, Y. (2005). Wnt/ $\beta$-catenin signaling in mesenchymal progenitors controls osteoblast and chondrocyte differentiation during vertebrate skeletogenesis. Dev. Cell 8, 739-750.

De Bari, C., and Dell'Accio, F. (2008). Cell therapy: A challenge in modern medicine. Biomed. Mater. Eng. 18, S11-S17.

De Bari, C., Dell'Accio, F., and Luyten, F.P. (2001a). Human periosteum-derived cells maintain phenotypic stability and chondrogenic potential throughout expansion regardless of donor age. Arthritis Rheum. 44, 85-95.

De Bari, C., Dell'Accio, F., Tylzanowski, P., and Luyten, F.P. (2001b). Multipotent mesenchymal stem cells from adult human synovial membrane. Arthritis Rheum. 44, 1928-1942.

De Bari, C., Dell'Accio, F., Vandenabeele, F., Vermeesch, J.R., Raymackers, J.M., and Luyten, F.P. (2003). Skeletal muscle repair by adult human mesenchymal stem cells from synovial membrane. J. Cell Biol. 160, 909-918.

De Bari, C., Dell'Accio, F., and Luyten, F.P. (2004). Failure of in vitro-differentiated mesenchymal stem cells from the synovial membrane to form ectopic stable cartilage in vivo. Arthritis Rheum. 50, 142-150.

De Bari, C., Dell'Accio, F., Vanlauwe, J., Eyckmans, J., Khan, I.M., Archer, C.W., Jones, E.A., McGonagle, D., Mitsiadis, T.A., Pitzalis, C., and Luyten, F.P. (2006). Mesenchymal multipotency of adult human periosteal cells demonstrated by single-cell lineage analysis. Arthritis Rheum. 54, 1209-1221.

De Bari, C., Dell'Accio, F., Karystinou, A., Guillot, P.V., Fisk, N.M., Jones, E.A., McGonagle, D., Khan, I.M., Archer, C.W., Mitsiadis, T.A., Donaldson, A.N., Luyten, F.P., and Pitzalis, C. (2008). A biomarker-based mathematical model to predict bone-forming potency of human synovial and periosteal mesenchymal stem cells. Arthritis Rheum. 58, 240-250.

Dell'Accio, F., De Bari, C., and Luyten, F.P. (2001). Molecular markers predictive of the capacity of expanded human articular chondrocytes to form stable cartilage in vivo. Arthritis Rheum. 44, 1608-1619.

Dell'Accio, F., De Bari, C., Eltawil, N.M., Vanhummelen, P., and Pitzalis, C. (2008). Identification of the molecular response of articular cartilage to injury, by microarray screening: Wnt-16 expression and signaling after injury and in osteoarthritis. Arthritis Rheum. 58, 1410-1421.

Denker, A.E., Haas, A.R., Nicoll, S.B., and Tuan, R.S. (1999). Chondrogenic differentiation of murine C3H10T1/2 multipotential mesenchymal cells. I. Stimulation by bone morphogenetic protein-2 in high-density micromass cultures. Differentiation 64, 67-76.

Derynck, R., and Miyazono, K. (2008). TGF- $\beta$ and the TGF- $\beta$ family. In R. Derynck and K. Miyazono, eds. Cold Spring Harbor Monograph Series 50: The TGF- $\beta$ Family. (Cold Spring Harbor Laboratory Press, New York) pp. 29-43.

Dominici, M., Le Blanc, K., Mueller, I., Slaper-Cortenbach, I., Marini, F., Krause, D., Deans, R., Keating, A., Prockop, D., and Horwitz, E. (2006). Minimal criteria for defining multipotent mesenchymal stromal cells: The International Society for Cellular Therapy position statement. Cytotherapy 8, 315-317.

Dong, Y.F., Soung Do, Y., Schwarz, E.M., O'Keefe, R.J., and Drissi, H. (2006). Wnt induction of chondrocyte hypertrophy through the Runx2 transcription factor. J. Cell. Physiol. 208, 77-86.

Eijken, M., Meijer, I.M., Westbroek, I., Koedam, M., Chiba, H., Uitterlinden, A.G., Pols, H.A., and Van Leeuwen, J.P. (2008). Wnt signaling acts and is regulated in a human osteoblast differentiation dependent manner. J. Cell. Biochem. 104, 568-579.

Engler, A.J., Sen, S., Sweeney, H.L., and Discher, D.E. (2006). Matrix elasticity directs stem cell lineage specification. Cell 126, 677-689.

Etheridge, S.L., Spencer, G.J., Heath, D.J., and Genever, P.G. (2004). Expression profiling and functional analysis of Wnt signaling mechanisms in mesenchymal stem cells. Stem Cells $22,849-860$.

Eyckmans, J., Roberts, S.J., Schrooten, J., and Luyten, F.P. (2010). A clinically relevant model of osteoinduction: A process requiring calcium phosphate and BMP/Wnt signalling. J. Cell. Mol. Med. 14, 1845-1856.

Feng, J., Iwama, A., Satake, M., and Kohu, K. (2009). MicroRNA-27 enhances differentiation of myeloblasts into granulocytes by post-transcriptionally downregulating Runx1. Br. J. Haematol. 145, 412-423.

Fiorina, P., Jurewicz, M., Augello, A., Vergani, A., Dada, S., La Rosa, S., Selig, M., Godwin, J., Law, K., Placidi, C., Smith, R.N., Capella, C., Rodig, S., Adra, C.N., Atkinson, M., Sayegh, M.H., and Abdi, R. (2009). Immunomodulatory function of bone marrow-derived mesenchymal stem cells in experimental autoimmune type 1 diabetes. J. Immunol. 183, 9931004.

Fischer, L., Boland, G., and Tuan, R.S. (2002). Wnt signaling during BMP-2 stimulation of mesenchymal chondrogenesis. J. Cell. Biochem. 84, 816-831.

Friedenstein, A.J., Chailakhjan, R.K., and Lalykina, K.S. (1970). The development of fibroblast colonies in monolayer cultures of guinea-pig bone marrow and spleen cells. Cell Tissue Kinet. 3, 393-403. 
Friedenstein, A.J., Gorskaja, J.F., and Kulagina, N.N. (1976). Fibroblast precursors in normal and irradiated mouse hematopoietic organs. Exp. Hematol. 4, 267-274.

Gindraux, F., Selmani, Z., Obert, L., Davani, S., Tiberghien, P., Herve, P., and Deschaseaux, F. (2007). Human and rodent bone marrow mesenchymal stem cells that express primitive stem cell markers can be directly enriched by using the CD49a molecule. Cell Tissue Res. 327, 471-483.

Gong, Y., Slee, R.B., Fukai, N., Rawadi, G., Roman-Roman, S., Reginato, A.M., Wang, H., Cundy, T., Glorieux, F.H., Lev, D., Zacharin, M., Oexle, K., Marcelino, J., Suwairi, W., Heeger, S., Sabatakos, G., Apte, S., Adkins, W.N., Allgrove, J., ArslanKirchner, M., Batch, J.A., Beighton, P., Black, G.C., Boles, R.G., Boon, L.M., Borrone, C., Brunner, H.G., Carle, G.F., Dallapiccola, B., De Paepe, A., Floege, B., Halfhide, M.L., Hall, B., Hennekam, R.C., Hirose, T., Jans, A., Juppner, H., Kim, C.A., Keppler-Noreuil, K., Kohlschuetter, A., Lacombe, D., Lambert, M., Lemyre, E., Letteboer, T., Peltonen, L., Ramesar, R.S., Romanengo, M., Somer, H., Steichen-Gersdorf, E., Steinmann, B., Sullivan, B., Superti-Furga, A., Swoboda, W., Van Den Boogaard, M.J., Van Hul, W., Vikkula, M., Votruba, M., Zabel, B., Garcia, T., Baron, R., Olsen, B.R., Warman, M.L., and Osteoporosis-Pseudoglioma Syndrome Collaborative Group. (2001). LDL receptor-related protein 5 (LRP5) affects bone accrual and eye development. Cell 107, 513-523.

Gordon, M.D., and Nusse, R. (2006). Wnt signaling: Multiple pathways, multiple receptors, and multiple transcription factors. J. Biol. Chem. 281, 22429-22433.

Gruber, R., Karreth, F., Kandler, B., Fuerst, G., Rot, A., Fischer, M.B., and Watzek, G. (2004). Platelet-released supernatants increase migration and proliferation, and decrease osteogenic differentiation of bone marrow-derived mesenchymal progenitor cells under in vitro conditions. Platelets 15, 29-35.

Haas, A.R., and Tuan, R.S. (1999). Chondrogenic differentiation of murine C3H10T1/2 multipotential mesenchymal cells. II. Stimulation by bone morphogenetic protein-2 requires modulation of $\mathrm{N}$-cadherin expression and function. Differentiation 64, 77-89.

Hanada, K., Dennis, J.E., and Caplan, A.I. (1997). Stimulatory effects of basic fibroblast growth factor and bone morphogenetic protein-2 on osteogenic differentiation of rat bone marrow-derived mesenchymal stem cells. J. Bone Miner. Res. 12, 1606-1614.

Haynesworth, S.E., Baber, M.A., and Caplan, A.I. (1992). Cell surface antigens on human marrow-derived mesenchymal cells are detected by monoclonal antibodies. Bone 13, 69-80.

Hill, T.P., Spater, D., Taketo, M.M., Birchmeier, W., and Hartmann, C. (2005). Canonical Wnt/ $\beta$-catenin signaling prevents osteoblasts from differentiating into chondrocytes. Dev. Cell 8, 727-738.

Hoeppner, L.H., Secreto, F.J., and Westendorf, J.J. (2009). Wnt signaling as a therapeutic target for bone diseases. Expert Opin. Ther. Targets 13, 485-496.

Hoffmann, A., Pelled, G., Turgeman, G., Eberle, P., Zilberman, Y., Shinar, H., Keinan-Adamsky, K., Winkel, A., Shahab, S., Navon, G., Gross, G., and Gazit, D. (2006). Neotendon formation induced by manipulation of the Smad8 signalling pathway in mesenchymal stem cells. J. Clin. Invest. 116, 940-952.

Hofstetter, C.P., Schwarz, E.J., Hess, D., Widenfalk, J., El Manira, A., Prockop, D.J., and Olson, L. (2002). Marrow stromal cells form guiding strands in the injured spinal cord and promote recovery. Proc. Natl. Acad. Sci. U.S.A. 99, 2199-2204.
Hogan, B.L. (1996). Bone morphogenetic proteins: Multifunctional regulators of vertebrate development. Genes Dev. 10, 1580-1594.

Holmen, S.L., Giambernardi, T.A., Zylstra, C.R., BucknerBerghuis, B.D., Resau, J.H., Hess, J.F., Glatt, V., Bouxsein, M.L., Ai, M., Warman, M.L., and Williams, B.O. (2004). Decreased BMD and limb deformities in mice carrying mutations in both Lrp5 and Lrp6. J. Bone Miner. Res. 19, 2033-2040.

Horner, A., Kemp, P., Summers, C., Bord, S., Bishop, N.J., Kelsall, A.W., Coleman, N., and Compston, J.E. (1998). Expression and distribution of transforming growth factor- $\beta$ isoforms and their signaling receptors in growing human bone. Bone 23, 95-102.

Im, G.I., and Quan, Z. (2010). The effects of Wnt inhibitors on the chondrogenesis of human mesenchymal stem cells. Tissue Eng. Part A 16, 2405-2413.

Jaiswal, N., Haynesworth, S.E., Caplan, A.I., and Bruder, S.P. (1997). Osteogenic differentiation of purified, cultureexpanded human mesenchymal stem cells in vitro. J. Cell. Biochem. 64, 295-312.

Johnstone, B., Hering, T.M., Caplan, A.I., Goldberg, V.M., and Yoo, J.U. (1998). In vitro chondrogenesis of bone marrowderived mesenchymal progenitor cells. Exp. Cell Res. 238, 265-272.

Jones, E.A., Kinsey, S.E., English, A., Jones, R.A., Straszynski, L., Meredith, D.M., Markham, A.F., Jack, A., Emery, P., and McGonagle, D. (2002). Isolation and characterization of bone marrow multipotential mesenchymal progenitor cells. Arthritis Rheum. 46, 3349-3360.

Jorgensen, N.R., Henriksen, Z., Sorensen, O.H., and Civitelli, R. (2004). Dexamethasone, BMP-2, and 1,25-dihydroxyvitamin D enhance a more differentiated osteoblast phenotype: Validation of an in vitro model for human bone marrow-derived primary osteoblasts. Steroids 69, 219-226.

Kahler, R.A., and Westendorf, J.J. (2003). Lymphoid enhancer factor-1 and $\beta$-catenin inhibit Runx2-dependent transcriptional activation of the osteocalcin promoter. J. Biol. Chem. 278, 11937-11944.

Kahler, R.A., Galindo, M., Lian, J., Stein, G.S., Van Wijnen, A.J., and Westendorf, J.J. (2006). Lymphocyte enhancer-binding factor 1 (Lef1) inhibits terminal differentiation of osteoblasts. J. Cell. Biochem. 97, 969-983.

Kahler, R.A., Yingst, S.M., Hoeppner, L.H., Jensen, E.D., Krawczak, D., Oxford, J.T., and Westendorf, J.J. (2008). Collagen 11a1 is indirectly activated by lymphocyte enhancerbinding factor 1 (Lef1) and negatively regulates osteoblast maturation. Matrix Biol. 27, 330-338.

Kapinas, K., Kessler, C., Ricks, T., Gronowicz, G., and Delany, A.M. (2010). miR-29 modulates Wnt signaling in human osteoblasts through a positive feedback loop. J. Biol. Chem. 285, 25221-25231.

Karsenty, G. (2008). Transcriptional control of skeletogenesis. Annu. Rev. Genomics Hum. Genet. 9, 183-196.

Karystinou, A., Dell'Accio, F., Kurth, T.B., Wackerhage, H., Khan, I.M., Archer, C.W., Jones, E.A., Mitsiadis, T.A., and De Bari, C. (2009). Distinct mesenchymal progenitor cell subsets in the adult human synovium. Rheumatology (Oxford) 48, 1057-1064.

Katagiri, T., and Miyazono, K. (2008). The bone morphogenetic proteins. In R. Derynck and K. Miyazono, eds. Cold Spring Harbor Monograph Series 50: The TGF- $\beta$ Family. (Cold Spring Harbor Laboratory Press, New York) pp. 121-149.

Kato, M., Patel, M.S., Levasseur, R., Lobov, I., Chang, B.H., Glass, D.A., II, Hartmann, C., Li, L., Hwang, T.H., Brayton, 
C.F., Lang, R.A., Karsenty, G., and Chan, L. (2002). Cbfa1independent decrease in osteoblast proliferation, osteopenia, and persistent embryonic eye vascularization in mice deficient in Lrp5, a Wnt coreceptor. J. Cell Biol. 157, 303-314.

Klees, R.F., Salasznyk, R.M., Kingsley, K., Williams, W.A., Boskey, A., and Plopper, G.E. (2005). Laminin-5 induces osteogenic gene expression in human mesenchymal stem cells through an ERK-dependent pathway. Mol. Biol. Cell 16, 881-890.

Komori, T. (2010). Regulation of bone development and extracellular matrix protein genes by RUNX2. Cell Tissue Res. 339, 189-195.

Kon, E., Muraglia, A., Corsi, A., Bianco, P., Marcacci, M., Martin, I., Boyde, A., Ruspantini, I., Chistolini, P., Rocca, M., Giardino, R., Cancedda, R., and Quarto, R. (2000). Autologous bone marrow stromal cells loaded onto porous hydroxyapatite ceramic accelerate bone repair in critical-size defects of sheep long bones. J. Biomed. Mater. Res. 49, 328-337.

Krampera, M., Pasini, A., Rigo, A., Scupoli, M.T., Tecchio, C., Malpeli, G., Scarpa, A., Dazzi, F., Pizzolo, G., and Vinante, F. (2005). HB-EGF/HER-1 signaling in bone marrow mesenchymal stem cells: Inducing cell expansion and reversibly preventing multilineage differentiation. Blood 106, 59-66.

Kratchmarova, I., Blagoev, B., Haack-Sorensen, M., Kassem, M., and Mann, M. (2005). Mechanism of divergent growth factor effects in mesenchymal stem cell differentiation. Science 308, 1472-1477.

Lecanda, F., Avioli, L.V., and Cheng, S.L. (1997). Regulation of bone matrix protein expression and induction of differentiation of human osteoblasts and human bone marrow stromal cells by bone morphogenetic protein-2. J. Cell. Biochem. 67, 386-396.

Little, R.D., Carulli, J.P., Del Mastro, R.G., Dupuis, J., Osborne, M., Folz, C., Manning, S.P., Swain, P.M., Zhao, S.C., Eustace, B., Lappe, M.M., Spitzer, L., Zweier, S., Braunschweiger, K., Benchekroun, Y., Hu, X., Adair, R., Chee, L., Fitzgerald, M.G., Tulig, C., Caruso, A., Tzellas, N., Bawa, A., Franklin, B., McGuire, S., Nogues, X., Gong, G., Allen, K.M., Anisowicz, A., Morales, A.J., Lomedico, P.T., Recker, S.M., Van Eerdewegh, P., Recker, R.R., and Johnson, M.L. (2002). A mutation in the LDL receptor-related protein 5 gene results in the autosomal dominant high-bone-mass trait. Am. J. Hum. Genet. 70, 11-19.

Liu, G., Vijayakumar, S., Grumolato, L., Arroyave, R., Qiao, H., Akiri, G., and Aaronson, S.A. (2009). Canonical Wnts function as potent regulators of osteogenesis by human mesenchymal stem cells. J. Cell Biol. 185, 67-75.

Lutz, M., and Knaus, P. (2002). Integration of the TGF- $\beta$ pathway into the cellular signalling network. Cell. Signal. 14, 977988.

Mackay, A.M., Beck, S.C., Murphy, J.M., Barry, F.P., Chichester, C.O., and Pittenger, M.F. (1998). Chondrogenic differentiation of cultured human mesenchymal stem cells from marrow. Tissue Eng. 4, 415-428.

Majumdar, M.K., Wang, E., and Morris, E.A. (2001). BMP-2 and BMP-9 promote chondrogenic differentiation of human multipotential mesenchymal cells and overcomes the inhibitory effect of IL-1. J. Cell. Physiol. 189, 275-284.

Martin, I., Muraglia, A., Campanile, G., Cancedda, R., and Quarto, R. (1997). Fibroblast growth factor-2 supports ex vivo expansion and maintenance of osteogenic precursors from human bone marrow. Endocrinology 138, 4456-4462.

Maruyama, T., Mirando, A.J., Deng, C.X., and Hsu, W. (2010). The balance of WNT and FGF signaling influences mesenchymal stem cell fate during skeletal development. Sci. Signal. 3 , ra40.
McDaneld, T.G., Smith, T.P., Doumit, M.E., Miles, J.R., Coutinho, L.L., Sonstegard, T.S., Matukumalli, L.K., Nonneman, D.J., and Wiedmann, R.T. (2009). MicroRNA transcriptome profiles during swine skeletal muscle development. BMC Genomics 10, 77.

Miyazono, K., Kamiya, Y., and Morikawa, M. (2010). Bone morphogenetic protein receptors and signal transduction. J. Biochem. 147, 35-51.

Mizuno, Y., Yagi, K., Tokuzawa, Y., Kanesaki-Yatsuka, Y., Suda, T., Katagiri, T., Fukuda, T., Maruyama, M., Okuda, A., Amemiya, T., Kondoh, Y., Tashiro, H., and Okazaki, Y. (2008). miR-125b inhibits osteoblastic differentiation by down-regulation of cell proliferation. Biochem. Biophys. Res. Commun. 368, 267-272.

Modarresi, R., Lafond, T., Roman-Blas, J.A., Danielson, K.G., Tuan, R.S., and Seghatoleslami, M.R. (2005). N-cadherin mediated distribution of $\beta$-catenin alters MAP kinase and BMP-2 signaling on chondrogenesis-related gene expression. J. Cell. Biochem. 95, 53-63.

Muraglia, A., Martin, I., Cancedda, R., and Quarto, R. (1998). A nude mouse model for human bone formation in unloaded conditions. Bone 22, 131S-134S.

Muraglia, A., Cancedda, R., and Quarto, R. (2000). Clonal mesenchymal progenitors from human bone marrow differentiate in vitro according to a hierarchical model. J. Cell Sci. 113, 11611166.

Nakahara, H., Dennis, J.E., Bruder, S.P., Haynesworth, S.E., Lennon, D.P., and Caplan, A.I. (1991). In vitro differentiation of bone and hypertrophic cartilage from periosteal-derived cells. Exp. Cell Res. 195, 492-503.

$\mathrm{Ng}$, F., Boucher, S., Koh, S., Sastry, K.S., Chase, L., Lakshmipathy, U., Choong, C., Yang, Z., Vemuri, M.C., Rao, M.S., and Tanavde, V. (2008). PDGF, TGF- $\beta$, and FGF signaling is important for differentiation and growth of mesenchymal stem cells (MSCs): Transcriptional profiling can identify markers and signaling pathways important in differentiation of MSCs into adipogenic, chondrogenic, and osteogenic lineages. Blood 112, 295-307.

Noth, U., Osyczka, A.M., Tuli, R., Hickok, N.J., Danielson, K.G., and Tuan, R.S. (2002). Multilineage mesenchymal differentiation potential of human trabecular bone-derived cells. J. Orthop. Res. 20, 1060-1069.

Ohgushi, H., and Okumura, M. (1990). Osteogenic capacity of rat and human marrow cells in porous ceramics: Experiments in athymic (nude) mice. Acta Orthop. Scand. 61, 431-434.

Peister, A., Mellad, J.A., Larson, B.L., Hall, B.M., Gibson, L.F., and Prockop, D.J. (2004). Adult stem cells from bone marrow (MSCs) isolated from different strains of inbred mice vary in surface epitopes, rates of proliferation, and differentiation potential. Blood 103, 1662-1668.

Pelttari, K., Winter, A., Steck, E., Goetzke, K., Hennig, T., Ochs, B.G., Aigner, T., and Richter, W. (2006). Premature induction of hypertrophy during in vitro chondrogenesis of human mesenchymal stem cells correlates with calcification and vascular invasion after ectopic transplantation in SCID mice. Arthritis Rheum. 54, 3254-3266.

Phinney, D.G., and Prockop, D.J. (2007). Concise review: Mesenchymal stem/multipotent stromal cells: The state of transdifferentiation and modes of tissue repair-current views. Stem Cells 25, 2896-2902.

Piek, E., Heldin, C.H., and Ten Dijke, P. (1999). Specificity, diversity, and regulation in TGF- $\beta$ superfamily signaling. FASEB J. 13, 2105-2124. 
Pittenger, M.F., Mackay, A.M., Beck, S.C., Jaiswal, R.K., Douglas, R., Mosca, J.D., Moorman, M.A., Simonetti, D.W., Craig, S., and Marshak, D.R. (1999). Multilineage potential of adult human mesenchymal stem cells. Science 284, 143-147.

Platt, M.O., Roman, A.J., Wells, A., Lauffenburger, D.A., and Griffith, L.G. (2009). Sustained epidermal growth factor receptor levels and activation by tethered ligand binding enhances osteogenic differentiation of multi-potent marrow stromal cells. J. Cell. Physiol. 221, 306-317.

Prockop, D.J. (1997). Marrow stromal cells as stem cells for nonhematopoietic tissues. Science 276, 71-74.

Qiu, Y.S., Shahgaldi, B.F., Revell, W.J., and Heatley, F.W. (2003). Observations of subchondral plate advancement during osteochondral repair: A histomorphometric and mechanical study in the rabbit femoral condyle. Osteoarthritis Cartilage $11,810-820$.

Quarto, N., Behr, B., and Longaker, M.T. (2010). Opposite spectrum of activity of canonical Wnt signaling in the osteogenic context of undifferentiated and differentiated mesenchymal cells: Implications for tissue engineering. Tissue Eng. Part A (in press). doi: 10.1089/ten.tea.2010.0133.

Quarto, R., Mastrogiacomo, M., Cancedda, R., Kutepov, S.M., Mukhachev, V., Lavroukov, A., Kon, E., and Marcacci, M. (2001). Repair of large bone defects with the use of autologous bone marrow stromal cells. N. Engl. J. Med. 344, 385-386.

Quintana, L., Zur Nieden, N.I., and Semino, C.E. (2009). Morphogenetic and regulatory mechanisms during developmental chondrogenesis: New paradigms for cartilage tissue engineering. Tissue Eng. Part B. Rev. 15, 29-41.

Rebelatto, C.K., Aguiar, A.M., Moretao, M.P., Senegaglia, A.C., Hansen, P., Barchiki, F., Oliveira, J., Martins, J., Kuligovski, C., Mansur, F., Christofis, A., Amaral, V.F., Brofman, P.S., Goldenberg, S., Nakao, L.S., and Correa, A. (2008). Dissimilar differentiation of mesenchymal stem cells from bone marrow, umbilical cord blood, and adipose tissue. Exp. Biol. Med. (Maywood) 233, 901-913.

Rickard, D.J., Sullivan, T.A., Shenker, B.J., Leboy, P.S., and Kazhdan, I. (1994). Induction of rapid osteoblast differentiation in rat bone marrow stromal cell cultures by dexamethasone and BMP-2. Dev. Biol. 161, 218-228.

Satomura, K., Derubeis, A.R., Fedarko, N.S., Ibaraki-O'Connor, K., Kuznetsov, S.A., Rowe, D.W., Young, M.F., and Gehron Robey, P. (1998). Receptor tyrosine kinase expression in human bone marrow stromal cells. J. Cell. Physiol. 177, 426-438.

Schmierer, B., and Hill, C.S. (2007). TGF $\beta$-SMAD signal transduction: Molecular specificity and functional flexibility. Nat. Rev. Mol. Cell Biol. 8, 970-982.

Schroeder, T.M., Jensen, E.D., and Westendorf, J.J. (2005). Runx2: A master organizer of gene transcription in developing and maturing osteoblasts. Birth Defects Res. C Embryo Today 75, 213-225.

Scotti, C., Tonnarelli, B., Papadimitropoulos, A., Scherberich, A., Schaeren, S., Schauerte, A., Lopez-Rios, J., Zeller, R., Barbero, A., and Martin, I. (2010). Recapitulation of endochondral bone formation using human adult mesenchymal stem cells as a paradigm for developmental engineering. Proc. Natl. Acad. Sci. U.S.A. 107, 7251-7256.

Sekiya, I., Colter, D.C., and Prockop, D.J. (2001). BMP-6 enhances chondrogenesis in a subpopulation of human marrow stromal cells. Biochem. Biophys. Res. Commun. 284, 411-418.

Sekiya, I., Vuoristo, J.T., Larson, B.L., and Prockop, D.J. (2002). In vitro cartilage formation by human adult stem cells from bone marrow stroma defines the sequence of cellular and molecular events during chondrogenesis. Proc. Natl. Acad. Sci. U.S.A. 99, 4397-4402.

Sekiya, I., Larson, B.L., Vuoristo, J.T., Reger, R.L., and Prockop, D.J. (2005). Comparison of effect of BMP-2, -4 , and -6 on in vitro cartilage formation of human adult stem cells from bone marrow stroma. Cell Tissue Res. 320, 269-276.

Shea, C.M., Edgar, C.M., Einhorn, T.A., and Gerstenfeld, L.C. (2003). BMP treatment of C3H10T1/2 mesenchymal stem cells induces both chondrogenesis and osteogenesis. J. Cell. Biochem. 90, 1112-1127.

Sibilia, M., Wagner, B., Hoebertz, A., Elliott, C., Marino, S., Jochum, W., and Wagner, E.F. (2003). Mice humanised for the EGF receptor display hypomorphic phenotypes in skin, bone and heart. Development 130, 4515-4525.

Song, L., Webb, N.E., Song, Y., and Tuan, R.S. (2006). Identification and functional analysis of candidate genes regulating mesenchymal stem cell self-renewal and multipotency. Stem Cells 24, 1707-1718.

Sundelacruz, S., Levin, M., and Kaplan, D.L. (2008). Membrane potential controls adipogenic and osteogenic differentiation of mesenchymal stem cells. PLoS One 3, e3737.

Sundelacruz, S., Levin, M., and Kaplan, D.L. (2009). Role of membrane potential in the regulation of cell proliferation and differentiation. Stem Cell Rev. 5, 231-246.

Sung, J.H., Yang, H.M., Park, J.B., Choi, G.S., Joh, J.W., Kwon, C.H., Chun, J.M., Lee, S.K., and Kim, S.J. (2008). Isolation and characterization of mouse mesenchymal stem cells. Transplant. Proc. 40, 2649-2654.

Takada, I., Kouzmenko, A.P., and Kato, S. (2009). Wnt and PPAR $\gamma$ signaling in osteoblastogenesis and adipogenesis. Nat. Rev. Rheumatol. 5, 442-447.

Tamama, K., Fan, V.H., Griffith, L.G., Blair, H.C., and Wells, A. (2006). Epidermal growth factor as a candidate for ex vivo expansion of bone marrow-derived mesenchymal stem cells. Stem Cells 24, 686-695.

Tokunaga, A., Oya, T., Ishii, Y., Motomura, H., Nakamura, C., Ishizawa, S., Fujimori, T., Nabeshima, Y., Umezawa, A., Kanamori, M., Kimura, T., and Sasahara, M. (2008). PDGF receptor $\beta$ is a potent regulator of mesenchymal stromal cell function. J. Bone Miner. Res. 23, 1519-1528.

Tuan, R.S. (2003). Cellular signaling in developmental chondrogenesis: N-cadherin, Wnts, and BMP-2. J. Bone Joint Surg. Am. 85-A(Suppl. 2), 137-141.

Tuli, R., Tuli, S., Nandi, S., Huang, X., Manner, P.A., Hozack, W.J., Danielson, K.G., Hall, D.J., and Tuan, R.S. (2003). Transforming growth factor- $\beta$-mediated chondrogenesis of human mesenchymal progenitor cells involves $\mathrm{N}$-cadherin and mitogen-activated protein kinase and Wnt signaling cross-talk. J. Biol. Chem. 278, 41227-41236.

Wakitani, S., Saito, T., and Caplan, A.I. (1995). Myogenic cells derived from rat bone marrow mesenchymal stem cells exposed to 5-azacytidine. Muscle Nerve 18, 1417-1426.

Wang, E.A., Israel, D.I., Kelly, S., and Luxenberg, D.P. (1993). Bone morphogenetic protein-2 causes commitment and differentiation in C3H10T1/2 and 3T3 cells. Growth Factors 9, 57-71.

Wang, S., Kawashima, N., Sakamoto, K., Katsube, K.I., Umezawa, A., and Suda, H. (2010). Osteogenic differentiation of mouse mesenchymal progenitor cell, Kusa-A1 is promoted by mammalian transcriptional repressor Rbpj. Biochem. Biophys. Res. Commun. 400, 39-45.

Wang, T., and $\mathrm{Xu}, \mathrm{Z}$. (2010). miR-27 promotes osteoblast differentiation by modulating Wnt signaling. Biochem. Biophys. Res. Commun. (in press). doi: 10.1016/j.bbrc.2010.08.031. 
Westendorf, J.J., Kahler, R.A., and Schroeder, T.M. (2004). Wnt signaling in osteoblasts and bone diseases. Gene 341, 19-39.

Xiao, Y.T., Xiang, L.X., and Shao, J.Z. (2007). Bone morphogenetic protein. Biochem. Biophys. Res. Commun. 362, 550-553.

Yadav, V.K., Ryu, J.H., Suda, N., Tanaka, K.F., Gingrich, J.A., Schutz, G., Glorieux, F.H., Chiang, C.Y., Zajac, J.D., Insogna, K.L., Mann, J.J., Hen, R., Ducy, P., and Karsenty, G. (2008). Lrp5 controls bone formation by inhibiting serotonin synthesis in the duodenum. Cell 135, 825-837.

Yoo, K.H., Jang, I.K., Lee, M.W., Kim, H.E., Yang, M.S., Eom, Y., Lee, J.E., Kim, Y.J., Yang, S.K., Jung, H.L., Sung, K.W., Kim, C.W., and Koo, H.H. (2009). Comparison of immunomodulatory properties of mesenchymal stem cells derived from adult human tissues. Cell. Immunol. 259, 150-156.

Zhao, M., Harris, S.E., Horn, D., Geng, Z., Nishimura, R., Mundy, G.R., and Chen, D. (2002). Bone morphogenetic protein receptor signaling is necessary for normal murine postnatal bone formation. J. Cell Biol. 157, 1049-1060.
Zuk, P.A., Zhu, M., Ashjian, P., De Ugarte, D.A., Huang, J.I., Mizuno, H., Alfonso, Z.C., Fraser, J.K., Benhaim, P., and Hedrick, M.H. (2002). Human adipose tissue is a source of multipotent stem cells. Mol. Biol. Cell 13, 4279-4295.

\author{
Address correspondence to: \\ Dr. Cosimo De Bari \\ Institute of Medical Sciences \\ Foresterhill \\ Aberdeen AB25 2ZD, UK \\ E-mail: c.debari@abdn.ac.uk
}

Received for publication August 26, 2010; accepted August 30, 2010.

Published online: September 23, 2010. 
